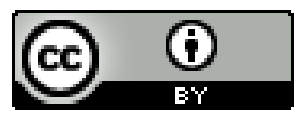

\title{
TRAMAS DE LIBERDADE: ALFORRIA, TRABALHO E SOLIDARIEDADE NO GRÃO-PARÁ (1850-1890)
}

\author{
Marcelo Ferreira Lobo ${ }^{1}$
}

\begin{abstract}
Resumo: Este artigo discute a mobilidade de escravos e libertos no Grão-Pará oitocentista e a construção de redes vinculadas ao mundo do trabalho amazônico. Ao analisar 1866 testamentos na província paraense entre os anos de 1796 a 1888, foi possível reconstruir fragmentos de trajetórias de dezenas de sujeitos que transitaram entre a escravidão e liberdade. Neste sentido a presença de libertos no mercado urbano de trabalho na capital paraense, propiciou uma série de tensões marcados pela origem, cor e classe. A figura do liberto ganha destaque como sujeito capaz de mobilizar capital social afim de alargar suas noções de diretos, e acesso a espaços restritos, ampliando as noções do ser cidadão.
\end{abstract}

Palavras Chaves: Libertos, Mobilidade, Redes, Cidadania.

\section{PLOTS OF FREEDOM: MANUMISSION, WORK AND SOLIDARITY IN GRÃO-PARÁ (1850-1890)}

\begin{abstract}
This article discusses the mobility of slaves and freedmen in 19th century Grão-Pará and the construction of networks linked to the world of Amazonian labor. When analyzing 1866 wills in the province of Pará between the years 1796 to 1888, it was possible to reconstruct fragments of the trajectories of dozens of subjects who moved between slavery and freedom. In this sense, the presence of freedmen in the urban labor market in the capital of Pará, caused a series of tensions marked by origin, color and class. The figure of the freed person gains prominence as a subject capable of mobilizing social capital in order to broaden his notions of rights, and access to restricted spaces, expanding the notions of being a citizen.
\end{abstract}

Keywords: Freedmen, Mobility, Networks, Citizenship.

\section{TRAMAS DE LIBERTAD: MANUMISIÓN, TRABAJO Y SOLIDARIDAD EN GRÃO-PARÁ (1850-1890)}

\footnotetext{
${ }^{1}$ Doutor em História Social da Amazônia pelo Programa de Pós-Graduação em História da Universidade Federal do Pará, membro do Grupo de Estudos e Pesquisas da Escravidão e Abolicionismo na Amazônia (GEPEAM). ORCID https://orcid.org/0000-0002-6827-3182. E-mail: $\underline{\text { m.lobo2013@ outlook.com }}$
}

Revista da ABPN • v. 12, n. Ed. Especial - Caderno Temático: "Africanos, escravizados, libertos biografias, imagens e experiências atlânticas” • agosto de 2020, p. $344-369$ 
Resumen: Este artículo analiza la movilidad de esclavos y libertos en Grão-Pará del siglo XIX y la construcción de redes vinculadas al mundo de la mano de obra amazónica. Al analizar las voluntades de 1866 en la provincia de Pará entre los años 1796 a 1888, fue posible reconstruir fragmentos de las trayectorias de docenas de sujetos que se movieron entre la esclavitud y la libertad. En este sentido, la presencia de libertos en el mercado laboral urbano de la capital de Pará, provocó una serie de tensiones marcadas por origen, color y clase. La figura de la persona liberada adquiere protagonismo como sujeto capaz de movilizar capital social para ampliar sus nociones de derechos y acceder a espacios restringidos, ampliando las nociones de ser ciudadano.

Palabras clave: Libertos, Movilidad, Redes, Ciudadanía.

\section{LOTS DE LIBERTÉ: ALFORRIA, TRAVAIL ET SOLIDARITÉ À GRÃO- PARÁ (1850-1890)}

Résumé: Cet article traite de la mobilité des esclaves et des affranchis dans le Grão-Pará au XIXe siècle et la construction de réseaux liés au monde du travail amazonien. En analysant les testaments de 1866 dans la province du Pará entre les années 1796 et 1888, il a été possible de reconstituer des fragments des trajectoires de dizaines de sujets qui ont évolué entre l'esclavage et la liberté. En ce sens, la présence des affranchis sur le marché du travail urbain de la capitale du Pará a provoqué une série de tensions marquées par l'origine, la couleur et la classe. La figure de la personne libérée gagne en importance en tant que sujet capable de mobiliser le capital social afin d'élargir ses notions de droits et d'accès à des espaces restreints, élargissant les notions de citoyen.

Mots-clés: Libérés, Mobilité, Réseaux, Citoyenneté;

\section{INTRODUÇÃO}

Entre os muitos libertos que apareceram nos jornais de Belém ao longo do século XIX, o preto Thomás Gonçalo havia despertado a atenção de maneira mais acentuada. Em 1859 alguns periódicos de Belém noticiavam a partida para Hamburgo do "preto", ou do "liberto" Thomás. O que estaria fazendo ao embarcar em direção a um país com características tão distintas do Brasil? Alguns estudos têm demonstrado a participação de ex-escravos no comércio atlântico, e particularmente no tráfico negreiro (Reis; Carvalho \& Gomes, 2017). ${ }^{2}$ É necessário frisar que a participação de libertos e livres de cor no comércio atlântico foi além da questão do tráfico de escravos, muitos braços fizeram-se necessários para transportar os inúmeros produtos do Brasil para além mar.

\footnotetext{
${ }^{2}$ O trabalho de João José Reis, Marcus de Carvalho e Flavio Gomes, sobre o alufá Rufino constrói um excelente panorama da participação de libertos e escravos no comércio Marítimo.
}

Revista da ABPN • v. 12, n. Ed. Especial - Caderno Temático: "Africanos, escravizados, libertos biografias, imagens e experiências atlânticas” • agosto de 2020, p. 344-369 
Estivadores, marinheiros, práticos e cozinheiros eram sujeitos que por vezes tinham no seu passado as marcas da escravidão.

Figura 1- Partida do Brigue Otto

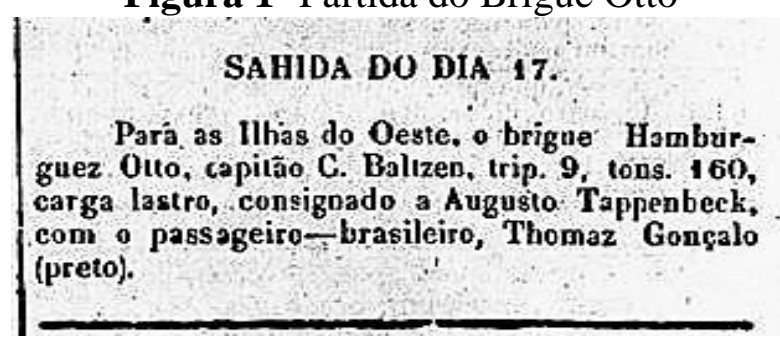

Fonte: Gazeta Oficcial (PA), 18/06/1859, p. 4.

Não foi a primeira viajem do Brigue Otto. Em 1855 partio de Belém para Hamburgo com um carregamento de 2.099 arrobas e 20 libras de borracha fina, 717 arrobas e 10 libras da entrefina, 123 arrobas e 21 libras da grossa, também constava na carga 1800 alqueires de castanhas, 517 arrobas e 20 libras de urucum, 68 libras de sementes, 6 de chocolate e 4 bengalas, todo o carregamento na valor de 47 contos e três mil e 150 réis. $^{3}$ Ele havia entrado nos portos de Belém em 30 de maio de 1855 , consignado a Augusto Tappembeck.

Em setembro de 1855 o Brigue retornou com um carregamento de queijos, fazendas de algodão, linho, quinquilharias, chapéus de palha, facas, tesouras, roupa feita, pedra de gesso, pregos, vinho, água de colônia, conhaque, papelão, vidro, objetos de ouro, conservas, garrafões, cerveja e entre vários produtos industrializados. ${ }^{4}$ Em janeiro de 1859 a referida embarcação havia exportado 26 contos e 181 mil réis em produtos. Dados de Sales e Mourão (2013) demonstram a circulação intensa de embarcações estrangeiras nos portos do Grão-Pará entre 1840 e 1870, neste período entraram 4.114 navios.

Na mesma medida que aumentava a importação, havia a exportação de produtos da floresta, a goma elástica (borracha), cacau, castanhas etc. Um emaranhado de trilhas compostas por rios e igarapés por vezes guiados por índios, africanos, escravos e

\footnotetext{
${ }^{3}$ Hemeroteca Digital da Biblioteca Nacional (daqui em diante lê-se HDBN). Treze de Maio (PA), 23/06/1855, p. 4.

${ }^{4}$ HDBN. Treze de Maio (PA), 10/09/1855, p. 4.
}

Revista da ABPN • v. 12, n. Ed. Especial - Caderno Temático: "Africanos, escravizados, libertos biografias, imagens e experiências atlânticas" • agosto de 2020, p. 344-369 
libertos levavam tais produtos ao porto de Belém, e o inverso acontecia com os regatões que vendiam os produtos importados no interior da província.

Comércio e navegação no Brasil oitocentista são termos intrinsecamente ligados, para além da troca de produtos, introduziam ideias por meio dos marinheiros e demais tripulantes. Por vezes encontrei libertos embarcando em direção a Lisboa, provavelmente acompanhando seus senhores, e quando retornavam ao Pará conseguiam atingir a condição de forros.

Há de se destacar que as relações entre o Pará e Portugal se mantiveram próximas mesmo após a adesão a independência de 1823, famílias portuguesas que se mantiveram e outras que entraram ao longo do século XIX, envolvidas no comércio e na política paraense. Em um conjunto de 1.866 testamentos levantados entre o período de 1796 a 1888 no Pará, os portugueses foram o segundo grupo depois dos nacionais que mais aparecem, contudo, o Grão-Pará passou a intensificar suas relações econômicas com as outras províncias assim como abriu-se a chegada de outros estrangeiros interessados em estabelecer comércio.

Em 1859 partia para Nantes na França Cecilia Porthé: Cecilia Porté, retira-se para França, na barca Brasileira, e declara que não deixa nesta praça pessoa alguma encarregada de seus negócios ${ }^{5}$. Partia levando consigo um menor, preto liberto, de nome Francisco. ${ }^{6}$ Dona de um restaurante francês no largo de Nazareth em Belém, nos jornais da capital paraense aparece se envolvendo em alguns negócios, sendo multada pela câmara municipal em decorrência do confinamento de certos animais em seu estabelecimento. As relações que escravos e libertos estabeleciam com seus senhores lhes possibilitava entrar em contato com diversos indivíduos e atividades, potencializando as experiencias de liberdade.

A mobilidade própria das pessoas livres demarcou um dos principais direitos negados a pessoas de cor no Brasil oitocentista. Se mover livremente pelo território sem o risco de ser preso sob suspeita de fuga, ou mesmo sem o risco de ser escravizado ilegalmente, eis um dos grandes limites aos libertos e livres de cor no Brasil oitocentista. Para Thomás Gonçalo o risco seria menor visto estar indo em direção ao além-mar.

\footnotetext{
${ }^{5}$ HDBN. Gazeta Offcial (PA), 21/06/1859, p.1.

${ }^{6}$ HDBN. Gazeta Offcial (PA), 17/06/1859, p.2.
}

Revista da ABPN • v. 12, n. Ed. Especial - Caderno Temático: "Africanos, 
As motivações de Thomás ficaram claras ao encontrar seu testamento feito em 1865. Sua estada em Hamburgo esteve associada aos negócios da firma Tappembeck. Em testamento declarou ter dívidas a serem pagas a Augusto Tappembeck residente em Liverpool.

Filho do preto Gonçalo e da preta Josefa, estes foram escravos de José Rodrigues Lima no rio Acará interior da província paraense. Em meio aos 50 testamentos de libertos levantados para o Grão-Pará oitocentista, não foi comum que os filhos de escravos efetivamente soubessem os nomes de seus pais. Recorrentemente nota-se nos termos de assentos de batismos de escravos a designação "pai incógnito", o fato de conhecer os nomes de seus pais indica que Thomas conviveu por um bom tempo na propriedade de seu antigo senhor, em 1865 sabia inclusive o paradeiro de seu irmão Rufino. Neste sentido é fácil construir a imagem de uma infância dedicada a produção de farinha, aguardente, ou extração de cacau, goma elástica e outros produtos da floresta, assim como o desenvolvimento de certa habilidade na navegação de rios e igarapés.

A região do rio Acará próxima a Belém, era parte da zona Guajarina, região do baixo amazonas. Área ocupada a partir de 1707, onde foram concedidas 245 sesmarias até 1824. É muito provável que os pais de Thomás tenham vivenciado os conflitos da revolta da Cabanagem (1835-1840), que no interior da província paraense se estendeu até meados da década de 1840. Embora esta região seja caracterizada pela concentração fundiária, composta de inúmeros engenhos dedicados a produção de aguardente, açúcar, e criação de gado, não foi incomum a existência de sítios, e pequenas propriedades que podem ser pensadas como um campesinato mestiço, composto por libertos, índios e seus descendentes.

Unidades de produção baseadas em uma economia familiar, estas estariam na margem da economia dos engenhos. Tanto que o liberto João Nepomuceno, durante a primeira metade do século XIX, comprou terras e trabalhou com sua família para pagar as mesmas no rio Mojú, também parte das cercanias de Belém. ${ }^{7}$ Rosário Lima (2002) chamou a atenção para a composição étnica diversificada da região, há um pequeno

\footnotetext{
${ }^{7}$ Arquivo Público do Estado do Pará (APEP). Juízo de Direito da $1^{\text {a }}$ Vara da Capital, Autos de Nulidade de testamento, 1876.
}

Revista da ABPN • v. 12, n. Ed. Especial - Caderno Temático: "Africanos, escravizados, libertos biografias, imagens e experiências atlânticas” • agosto de 2020, p. 344-369 
mundo camponês em questão e deve ser analisado para além dos grandes sesmeiros e do sistema de plantation.

Um cenário demarcado por rios, igarapés e furos, teve no sistema de agro extrativismo sua base econômica. Neste cenário é possível que ele e seus pais tenham trabalhado em engenhos, na produção de cachaça durante parte do ano e em outro momento na coleta de produtos da floresta.

Os pais de Thomas já eram falecidos quando fez o testamento em 1865, contava ele então ainda com um irmão chamado Rufino que era escravo da firma comercial Arch \& Campbell. Dentre seus bens possuía dois quartos de casas na Travessa do Passinho, os documentos de tal propriedade estavam em poder dos comerciantes Muller \& Cia que eram responsáveis por cobrar os aluguéis do imóvel.

Entre os testamentos de libertos levantados, verifiquei que a posse de imóveis como casas, ou terrenos eram comuns a 19 deles. Seriam estes os principais bens que possuíram ao longo da vida, por vezes nota-se que adquiriam os imóveis por meio de legados de antigos senhores.

Seja qual for a origem dos dois quartos de casas que Thomás possuía, ficou evidente em seu testamento a importância das relações que estabeleceu com várias casa comerciais da capital paraense. Trabalhava para a firma Tappenbeck, mantinha negócios com a firma Muller \& Cia, e seu irmão era escravo da casa comercial Arch \& Campbell. É provável que para além dos trabalhos que exerceu a bordo do Brigue Otto, tenha aproveitado a oportunidade para fazer negócios por conta própria. Reis, Marcus e Gomes (2017), demonstram em seu estudo sobre o africano Rufino, como parte da equipagem de embarcações transatlânticas também comercializavam em pequena escala produtos durante suas viagens.

Thomás possuía dívidas a serem pagas com Agusto Tappembeck que estava em Liverpool e com a firma Bento Villeré \& Cia. A presença cada vez mais frequente de casas comerciais no Pará oitocentista esteve vinculado a exploração da Borracha, e produtos agrícolas da região da zona Guajarina e ao crescimento demográfico de Belém. Por vezes tais casas comerciais vinculavam-se a escravidão por meio das relações com escravos e senhores. Em 1873 mais de 100 escravos haviam depositado cerca de 30

Revista da ABPN • v. 12, n. Ed. Especial - Caderno Temático: "Africanos, escravizados, libertos biografias, imagens e experiências atlânticas” • agosto de 2020, p. 344-369 
contos em pecúlios na firma Sá \& Cia, neste sentido o depósito de pecúlio em casas de comércios era uma prática utilizada por escravos e familiares (Lobo, 2011).

Entre os comerciantes mencionados no testamento de Thomás estavam os senhores Augusto Tappembeck, Bento Villaré e os Campbell. Convém mergulharmos no universo destes negociantes para entendermos as relações estabelecidas com o nosso liberto.

Bento Villaré era espanhol, natural de São Martinho. Em 1855 foi publicado breve nota sobre a abertura de uma nova casa de negócios na rua Santo Antônio em frente ao largo da Mercês entre os sócios Bento e José Dias Marques, não era o primeiro negócio do espanhol. ${ }^{8}$ Em 1856 em nome de sua firma Villaré \& $C^{a}$ foram comprados quatro escravos que estavam em fuga pertencentes a Luiz Antônio Henriques. ${ }^{9}$

Em várias notas publicadas nos jornais vê-se que a firma Villaré \& $C^{a}$ dedicava-se a importação e venda de alimentos como queijos e presuntos ingleses, doces, peixes, salsa, cebolas, batatas, azeites, também produtos como sebo, couro, ${ }^{10}$ um armazém. Seus negócios no Pará o tornaram um homem abastado, contava então em 1871 com o capital de 30 contos de reis em sua firma, mais 72 contos em dinheiro, apólices e letras. Em seu testamento alforriou seus três escravos Francisco, Cosme e Maria. Legou a Maria um conto de reis pelos bons serviços, também deixou a mulata Leonor, que esteve em sua casa durante certo tempo, 1 conto de réis. ${ }^{11}$

Além de Bento Villaré, o preto Thomás possuía relações com a família Tappembeck, não só viajou para Hamburgo em um navio consignado a Augusto Tappembeck como também declarou ter dívidas com ele. Augusto Tappembeck era natural de Bremen ${ }^{12}$ (Cidade-Estado ao norte da Alemanha), em 1859 o viajante Robert Avé -Lallemant foi procurar auxílio dos donos do único estabelecimento comercial alemão existente no Pará, ${ }^{13}$ do sr. Tappembeck, estes mandaram buscar a bagagem e o hospedaram em sua casa na mais bela rua do Pará, em sua obra ressaltou a atenção que

\footnotetext{
${ }^{8}$ HDBN. Treze de Maio (PA), 30/10/1855, p. 4.

${ }^{9}$ HDBN. Treze de Maio (PA), 19/04/1856, p. 4.

10 HDBN. Diário de Belém (PA); 24/06/1869, p.3; 25/05/1869, p.2; 21/04/1869, p. 3. Gazeta Official (PA), 07/04/1859, p. 4.

11 Centro de Memória da Amazônia (CMA). Fundo Testamentos; Testamento de Bento Villaré, 31/10/1871, caixa 19.

${ }^{12}$ HDBN. Treze de Maio (PA), 29/11/1848, p. 4.

${ }^{13}$ AVÉ-LALLEMANT, Robert. No Rio Amazonas (1859). Belo Horizonte: Ed. da Universidade de São Paulo, 1980.
}

Revista da ABPN • v. 12, n. Ed. Especial - Caderno Temático: "Africanos, escravizados, libertos biografias, imagens e experiências atlânticas” • agosto de 2020, p. 344-369 
recebera dos Tappembeck, não seria improvável que tenha cruzado com Thomás Gonçalo em algum momento de sua estadia em Belém.

Em 1855 o alemão, mestre carpinteiro, Wolfgaug Stumm publicou agradecimentos aos Tappembeck. Quando sua esposa e filhos ficaram doentes, Guilherme Tappembeck fez tudo que pode para dar suporte a eles, conseguindo um médico, já Augusto (apresentado como cônsul da Prússia) lhe emprestou a quantia de 100 mil reis com que conseguiu pagar as dívidas feitas pela doença e morte de seus filhos e mulher. ${ }^{14}$ Longe de determinar o caráter benevolente do patrão de Thomás, entrevemos ações de solidariedade entre imigrantes, desde a hospedagem dada ao viajante em 1859, ou o auxílio promovido ao infeliz Wolfgaug, ou mesmo a uma campanha de arrecadação para ajudar os órfãos da guerra entre França e Alemanha em $1870 . .^{15}$

O que se pode afirmar é que os Tamppenbeck foram figuras influentes, esta família representou o consulado austríaco e prussiano em Belém. Augusto, quando partiu para Liverpool, deixou seu irmão sobre tal encargo, possuía negócios na praça de Pernambuco e Maranhão. Foi para ele que Thomás deixou os aluguéis de seu quarto de casas até que sua dívida fosse quitada.

A vida de Thomas foi marcada pela presença de imigrantes, o seu herdeiro nomeado foi então o médico Andres Capper. Em outubro de 1860 a Câmara de Franca (comarcar do interior paraense) informava a secretaria da província acerca de uma epidemia que já havia matado 14 pessoas, e que algo semelhante ocorria em Santarém para onde deveria ser enviado o médico Antônio Andres Capper. ${ }^{16}$ Em 27 de fevereiro ele envia um ofício a Câmara municipal de Santarém dando conta do estado sanitário da Cidade e informando que não continuaria no comando da comissão se não fosse pago 600 mil réis mensais. ${ }^{17}$ No mesmo ano ele enviou seu escravo Basílio para Rio de Janeiro para servir a sua esposa e solicitou isenção do pagamento do imposto sobre o cativo.

Capper formou-se pela Faculdade de Medicina do Rio de Janeiro, em 1856 seu nome aparece em uma lista de alunos da referida instituição no Correio Mercantil,

\footnotetext{
${ }^{14}$ HDBN. Treze de Maio (PA), 20/02/1855, p. 2.

${ }^{15}$ HDBN. O Liberal do Pará (PA), 30/08/1870, p. 3.

${ }^{16}$ HDBN. Treze de Maio (PA), 30/03/1861, p. 1.

${ }^{17}$ HDBN. Treze de Maio (PA), 07/10/1861, p. 4.
}

Revista da ABPN • v. 12, n. Ed. Especial - Caderno Temático: "Africanos, escravizados, libertos biografias, imagens e experiências atlânticas” • agosto de 2020, p. $344-369$ 
estava no seu quarto ano de faculdade, ${ }^{18}$ concluiu seu estudo na instituição em $1858 .{ }^{19} \mathrm{E}$ em agosto de 1860 embarcou rumo ao Pará em companhia de seu escravo e outras figuras importantes como Tito Franco de Almeida, João Augusto Correa, Francisco de Araújo Lima. ${ }^{20}$

As redes na qual Thomás esteve inserido demonstram o grau de mobilidade, indo além da proteção senhorial, à medida que a economia da província crescia novas possibilidades de negócios surgiam, escravos e libertos participavam ativamente deste contexto. Entre os testamentos de libertos aqui levantados, encontrei pequenos agricultores, posseiros, comerciantes, carpinteiros, vendedoras de rua, cada qual inserido em redes verticais e horizontais. Thomás Gonçalo cercou-se por comerciantes estrangeiros, talvez não fosse uma escolha dele, contudo, se valeu de tal rede.

Para seu único parente vivo, seu irmão Rufino, que ainda era escravo de casa comercial Acrh \& Campbell, legou 400 mil reis a fim de ajudar na sua liberdade. Em 1865 com 400 mil réis era possível comprar em Belém um cativo com idade de 50 anos, os escravos entre 20 e 30 anos custavam por volta de 700 a 800 mil réis, de tal maneira que se Rufino fosse mais velho, estivesse na casa dos 40 anos estaria próximo a alcançar a liberdade, enquanto escravo de uma casa comercial seria pouco provável recusarem em aceitar a quantia pela alforria, ainda podendo usufruir dos serviços de Rufino como os Tappembeck valeram-se do preto Thomás.

A conquista da liberdade atrelada as redes nas quais Thomas esteve inserido, forneceram instrumentos que o permitiram viver sobre si. Do interior da província, da circulação por rios e igarapés até o grande "rio mar" atlântico, Thomás moveu-se espacial e socialmente ampliando as experiencias de liberdade no Grão-Pará oitocentista.

\section{ACEITO EM BOAS RODAS DA SOCIEDADE}

Durante a década de 1870 foi a vez do artista e comerciante Bertino Barboza de Lima ser atacado na imprensa de Belém por ser filho de uma escrava. Durante anos

\footnotetext{
${ }^{18}$ HDBN. Correio Mercantil (RJ), 14/05/1856, p. 3.

${ }^{19}$ HDBN. Diário do Rio de Janeiro (RJ), 26/11/1858, p. 1.

${ }^{20}$ HDBN. Correio Mercantil (RJ), 24/08/1860, p. 1.
}

Revista da ABPN • v. 12, n. Ed. Especial - Caderno Temático: "Africanos, escravizados, libertos biografias, imagens e experiências atlânticas" • agosto de 2020, p. 344-369 
trabalhou no largo da Basílica de Nazareth com uma firma intitulada Sociedade de Descanso, alugando cadeiras e vendendo produtos diversos no arraial.

Figura 2- Anúncio da Sociedade de Descanso

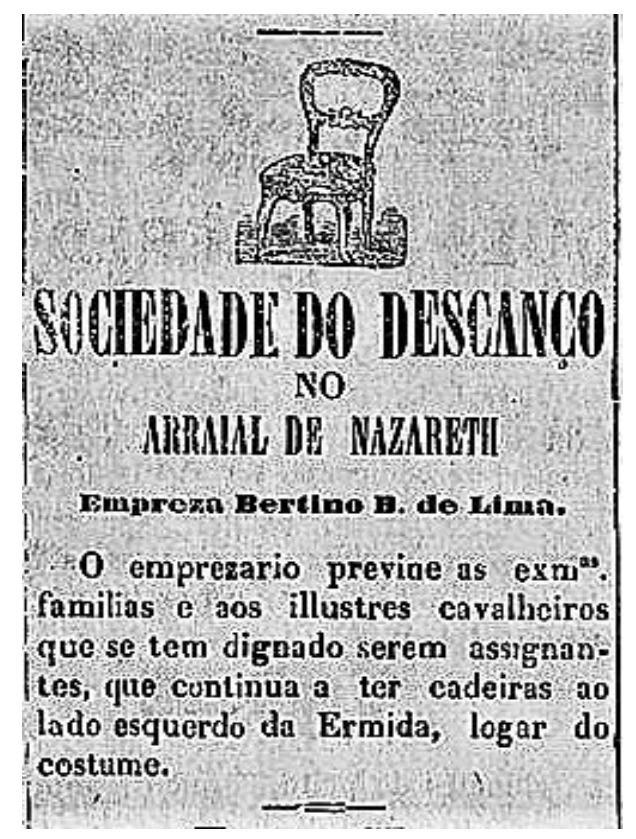

Fonte: Anúncio da empresa de Bertino, O Liberal do Pará (PA), 14/09/1870, p. 4

Em 1869 sob a assinatura de um soldado raso da democracia foi publicado na sessão a pedidos uma nota indicando três possíveis nomes a candidatos pelo Partido Liberal, seriam três paraenses ilustres; o Dr. José Coelho da Gama Abreu; Bertino Barboza de Lima e Bernardo José do Nascimento. O primeiro notável pelo seu talento, e virtudes cívicas e dos dois últimos seriam mártires de liberdade. $\mathrm{O}$ fato de Bertino ser liberto foi tomado como uma qualidade no sentido de martírio, ao ter passado de escravo para livre, ressaltando o ideal do mérito.

Em 1873 os redatores do jornal A tribuna do Povo, publicaram artigo intitulado $o$ moleque Bertino, no qual criticam o mesmo por seus posicionamentos a favor dos comerciantes portugueses de Belém, e o acusam de ser filho de uma preta. Bertino publicou sua resposta no jornal $O$ Santo Offício. Nota-se que para ele sua origem era tomada como algo negativo, embora ratifique não ter vergonha se sua origem.

Revista da ABPN • v. 12, n. Ed. Especial - Caderno Temático: "Africanos, escravizados, libertos biografias, imagens e experiências atlânticas" • agosto de 2020, 
Não sei a que proposito trouxe o pasquim de envolta com as descomposturas de minha cor?

Não está provado que sou mais claro que o capitão patusco?

Que culpa tenho eu de sair do ventre de uma preta, quando meu pai convinhalhe escolher o que melhor lhe agradasse?

Não tenho procurado desmentir esse meu passado do qual não me envergonho. Pois sou geralmente estimado por todas as pessoas sem distinção política? Não vê o senhor moleque agaloado, que o liberto é aceito em boas rodas e boas sociedades?

Bertino Barboza de Lima.

Bertino nascido de uma "preta escrava", chamada Sabina Maria. Isto remete as relações entre senhores e escravas que não foram raras, assim como os filhos escravos nascidos destas relações. O português Domingos da Silva foi casado com a preta Maria Caetana e não teve filhos; já Lourenço Antônio da Silva teve dois filhos com a parda liberta Ângela Maria, enquanto o Tenente Coronel João Antônio Luís Coelho mesmo casado teve filhos com a mulata escrava Victoria Maria, perfilhando os mesmos em testamento.

Seguindo a condição do ventre nasceram escravos e tiveram (mesmo sendo filho de senhores) que obter a alforria para gozar da condição de cidadão. A cor era silenciada, como indicado no capítulo anterior, a liberdade por si transformava pretos e mulatos em pardos e brancos.

"O Bertino" das cadeiras, como era conhecido evolvia-se com figuras ilustres da sociedade paraense, é possível que seu negócio instalado no largo de Nazaré tenha lhe propiciado manter contato com diversas autoridades locais, de maneira a fazer com que "o liberto fosse aceito nas boas rodas da sociedade".

A presença de figuras ilustres para os festejos em homenagem a Nossa Senhora de Nazaret mantinha Bertino próximo dos "bons círculos". Em 1878 o jornal A Boa Nova denunciava a presença de homens casados, pais de famílias em companhia de marafonas como o caso de um comendador "fidalgo que usa de uniforme encarnado", ele escolheu os dois melhores lugares da Sociedade de Descaço para "arullar" com uma "pombinha". 21

${ }^{21}$ HDBN. A Boa Nova (PA), 30/10/1878, p. 3.

Revista da ABPN • v. 12, n. Ed. Especial - Caderno Temático: "Africanos, escravizados, libertos biografias, imagens e experiências atlânticas” • agosto de 2020, p. 344-369 
A sociedade de Descanso funcionou de 1860 até pelo menos a década de 1940.

Em outubro de 1947 foi publicado no jornal O Liberal do Pará uma pequena nota sobre a sociedade de descanso:

Figura 3 - Sociedade de Descanso, século XX

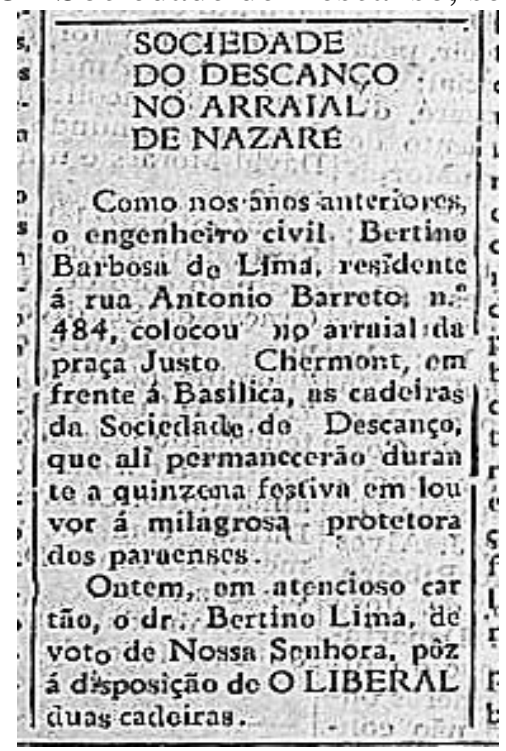

Fonte: O Liberal do Pará (PA), 16/10/1947, p. 3

O homônimo de Bertino em 1947 tratava-se de seu filho, que durante a década de 1890 estudou na Escola Politécnica da Bahia, trabalhando como engenheiro nas Obras Públicas do Estado. ${ }^{22}$ Neste sentido, destaca-se que a experiencia de libertos, ou negros, mulatos e pardos livres, mesmo que diante de uma precariedade estrutural da liberdade no século XIX, pode ser marcada por processos de mobilidade por meio do acesso a formação acadêmica (Silva, 2018).

A importância da festividade de Nazaré alagartava as redes de Bertino na medida em que figuras influentes da sociedade a participar da mesma. Neste caso para além de uma figura paterna que possibilitasse ao liberto Bertino a inserção na sociedade Belemense do oitocentos, foram as redes tecidas com políticos, e outras autoridades locais que possibilitaram a ele alcançar status e espaço político. Contudo, sua cor e sua origem foram acionadas para depreciar sua imagem.

Quanto das querelas em 1873 entre os redatores do jornal Tribuna e Bertino, vários artistas tomaram partido de Bertino, e assinaram em defesa da sua honra:

${ }^{22}$ HDBN. Mensagem do Governador do Pará para a assembleia (PA), 1929, p. 157.

Revista da ABPN • v. 12, n. Ed. Especial - Caderno Temático: "Africanos, escravizados, libertos biografias, imagens e experiências atlânticas” • agosto de 2020, p. $344-369$ 
Nós abaixo assinados, artistas e filhos desta capital, e outras do império, tendo deparado na leitura da Tribuna n. 14 de 7 do corrente, com um artigo que tem por título - Moleque Bertino - de onde se lê as mais asquerosas acusações feitas a esse artista, que por certo é bom amigo, pai carinhoso e extremoso esposo, cuida de exma. Família com maior desvelo, sem que por isso seja pesado a pessoa alguma; nos apressamos a apresentar-lhe os nossos comprimentos pela acertada resposta própria do artista independente, que ferido em seus ébrios e reputação trepida em comportar-se como fez aquele cavalheiro.

Belém 15 de abril de $1873 .^{23}$

Exatamente 38 pessoas assinaram a nota acima, entre eles vários membros da Imperial Sociedade Beneficente Artística Paraense. ${ }^{24}$ Pude identificar a presença de vários libertos nesta associação, que assim como Bertino puderam alavancar suas posições na sociedade paraense, ao saírem em defesa de um artista, membro de uma classe que estava se consolidando a partir da segunda metade do século XIX enquanto símbolos da valorização do trabalho, eles reforçavam o valor do trabalho e honra ao negar que a origem pudesse depreciar ou desqualificar o indivíduo.

Como demonstrarei a seguir a presença significativa de escravos em ocupações especializadas, e particularmente de cativos alforriados, introduziu ao longo do século XIX e especialmente nas últimas décadas um contingente de mão de obra qualificada no mercado urbano de Belém. Com o dinamismo da economia da borracha a cidade passou a proporcionar espaços de integração e mobilidade aos libertos enquadrados nas artes mecânicas.

Embora o uso de testamentos para discutir a trajetória de libertos e senhores tenha se mostrado na historiografia brasileira de fundamental importância, várias regiões do império brasileiro carecem de levantamentos mais contundentes, a fim de ampliar os debates sobre a condição de ser liberto no século XIX. Não só testamentos de libertos, mas também testamentos de senhores possibilitam encontrar os sujeitos em transição da escravidão para a liberdade.

O cônego Jeronimo Pimentel em seu testamento (1874) deixou forro o escravo Genésio Gens Pimentel filho da preta liberta Generosa. Também libertava todos seus escravos, para a mulata Generosa legou o quarto de casas na rua da pedreira $n^{\circ} 21$, legou

${ }^{23}$ HDBN. O Santo Offí́cio (PA), 21/04/1873, p. 4.

${ }^{24}$ A partir daqui tratarei a Imperial Sociedade Beneficente Artística Paraense por ISBAP.

Revista da ABPN • v. 12, n. Ed. Especial - Caderno Temático: "Africanos, escravizados, libertos biografias, imagens e experiências atlânticas” • agosto de 2020, p. 344-369 
outro quarto de casas na mesma rua a Manoel Pantaleão Pimentel e sua mãe a preta Marcelina. Tanto Manoel como Marcelina foram escravos de Jeronimo Pimentel. A Pompilho, também filho da preta Marcelina, outro quarto de casas na referida rua, $\mathrm{n}^{\mathbf{o}} 25$, ao pretinho Crisanto e ao preto Theodoro um quarto de casas na Travessa das Mercês. Tornou seu herdeiro universal Genésio Gens Pimentel e Manço Ribeiro Pimentel. ${ }^{25}$

Manoel Pantaleão aparece algumas vezes nos jornais de Belém. Em julho de 1876 faleceu de febre perniciosa o menor pardo, Carlos Augusto Pimentel, filho de Manoel Pantaleão e D. Maria Augusta de Almeida. ${ }^{26}$ Em dezembro de 1876, Manoel foi detido na cadeia pública de Belém incurso no crime de furto, ${ }^{27}$ e no primeiro semestre de 1877 ele foi levado ao júri sob acusação de estelionato, sob a defesa do advogado Samuel Wallace Mac-Dowell e apoio dos membros da Imperial Sociedade Beneficente Artística Paraense.

\footnotetext{
Agradecimento:

Venho por meio da imprensa agradecer a Sociedade Beneficente Artística Paraense o auxílio de esta dispensou por ocasião da perseguição que acabei de sofrer, e assim também ao muito distinto e ilustre Dr. Samuel W. Mac Dowell advogado da mesma sociedade, os esforços que empregou na minha defesa, por ocasião da última sessão do júri.

O pobre só pode pagar os favores que recebeu com a gratidão sincera de seu coração; pois bem, aceite o ilustre advogado e a humanitária associação estas linhas como sinal indelével do reconhecimento do abaixo assinado.

Belém, 15 de março de 1877.

Manuel Pantaleão Pimentel. ${ }^{28}$
}

A presença de libertos em associações de Artistas no século XIX demarca um dos primeiros espaços de associativismos compostos por homens de cor, para além das corporações de ofícios abolidas no início do século XIX. Por meio desta associação obteve o auxílio jurídico do ilustre emancipacionista paraense Samuel Wallace Mac Dowell.

Manoel faleceu em março de 1880, sendo velado pelos membros da associação: "na manhã de 8 do corrente a Imperial Sociedade Artística Beneficente Paraense manda

\footnotetext{
${ }^{25}$ CMA. Fundo Testamentos; Testamento de Jeronimo Roberto da Costa Pimentel, 1874, caixa 22.

${ }^{26}$ HDBN. A Constituição (PA), 19/07/1876, p. 1.

${ }^{27}$ HDBN. A Constituição (PA), 19/12/1876, p.1.

${ }^{28}$ HDBN. Diário de Belém (PA), 17/03/1877, p. 2.
}

Revista da ABPN • v. 12, n. Ed. Especial - Caderno Temático: "Africanos, escravizados, libertos biografias, imagens e experiências atlânticas" • agosto de 2020, p. $344-369$ 
celebrar uma missa em Sant'Anna por alma de seu finado socio Manoel Pantaleão Pimentel $^{29, "}$.

A relação entre escravos, libertos e a "classe artística" de Belém é fortalecida pela continua participação dos primeiros em ofícios tais como pedreiros, carpinas e ferreiros, as chamadas artes mecânicas. Os mestres de ofício por vezes eram escravos, libertos ou livres de cor. Ser qualificado em um determinado ofício possibilitava o ingresso no mundo do trabalho urbano, na mesma medida que possibilitava a participação em redes de apoio pautadas nas relações de trabalho. Vários cativos aparecem como mestres de ofício ou especializados em atividades ligadas as artes mecânicas. Em 1851, Salvador Rodrigues de Couto deixava liberto o Oficial de pedreiro Agostinho com a condição do mesmo dar trezentos mil réis no prazo de três anos, também libertou sem condição alguma Bernardino, oficial de pedreiro. ${ }^{30}$

Já em 1861 o escravo Eloy, oficial marceneiro, ficava forro com a condição de permanecer em companhia da esposa do testador. ${ }^{31}$ Em 1850 Antônia Rodrigues de Sousa deixou livre sua escrava chamada Anna, esta era casada com o preto Antônio Joaquim Oficial pedreiro, Ana foi nomeada a única herdeira dos bens de seu antigo senhor. $^{32}$

Em 1854 o escravo Benedito ficava livre após a prestação de serviços pelo prazo determinado:

Se eu morrer primeiro que meu pai, peço-lhe, que no fim de quatro anos, que lhe possuir o meu escravo Benedicto oficial de carpina, lhe mande dar pelo amor de Deus a carta de liberdade que as precisões de meus irmãos não o aflijam, pois que eles nunca fizeram sacrifício algum por seu ou meu respeito. ${ }^{33}$

No testamento de Claudina Rosa de Almeida, dentre os dez escravos listados, temos o escravo Alexandre. "Declaro que o meu mulato de nome Alexandre lhe faculto para que possa trabalhar no espaço de dois anos sem pagar semana peço a minha herdeira que lhe de esta faculdade por aquele tempo, não podendo jamais de afastar de

\footnotetext{
${ }^{29}$ HDBN. O Liberal do Pará (PA), 05/03/1880, p. 2.

30 CMA. Fundo Testamentos; Testamento de Salvador Rodrigues de Couto, 1851, caixa 08.

31 CMA. Fundo Testamentos; Testamento de José Ferreira da Costa, 1861. Caixa 15.

32 CMA. Fundo Testamentos; Testamento de Antônia Rodrigues de Sousa, 1850. Caixa 08.

33 CMA. Fundo Testamentos; Testamento de Duarte Antônio Gonçalves, 1854. Caixa 10.
}

Revista da ABPN • v. 12, n. Ed. Especial - Caderno Temático: "Africanos, escravizados, libertos biografias, imagens e experiências atlânticas” • agosto de 2020, p. 344-369 
sua companhia" ${ }^{34}$. Dentre os demais escravos mencionados, contavam Francisca, Virgolino, Joaquina, Joaquim, Leocádio, Lupércio e a mulata já forra Cândida Maria do Rosário.

Em 1880 é publicado no jornal Diário de Notícias uma nota sobre o falecimento de Cândida Maria do Rosário, na igreja do Rosário da campina será, hoje, ás 6 horas da manhã, será sufragada a alma da finada Cândida Maria do Rosário, a missa foi encomendada pelos seus filhos Joaquim José de Santa Anna, Virgolino Antônio de Souza e Francisca Gualdina. Entre os escravos de Claudia estavam três nomes que se repetiram na nota de falecimento de Cândida em 1885; Joaquim, Virgolino e Francisca, embora no testamento de 1846 não fique claro a origem materna destes três, é possível tratar-se dos filhos de Cândida.

Em duas listas de votantes publicadas no jornal $O$ Liberal do Pará nos anos de 1879 e 1880, Joaquim e Virgolino aparecem como votantes. O primeiro com 41 anos de idade, solteiro, oficial de carpina, sabia ler, era morador na rua das flores, mesma rua onde a antiga senhora de Cândida possuía três casas. Virgolino aparece com 37 anos, também oficial de carpina, morador na travessa nove de janeiro. Eles teriam em 1846 por volta de 7 e 5 anos de idade respectivamente. ${ }^{35}$

Ao ser um oficial de carpina estes libertos estavam dentro de um quadro maior, composto por milhares de escravos, libertos, e livres de cor que se dedicavam a artes mecânicas. Na segunda metade do século XIX uma nova ética do trabalho foi se configurando na sociedade do império, aos poucos a valorização de atividades mecânicas, na mesma medida em que se discutia a questão do elemento servil, foi sendo debatido e formulando propostas para a formação de uma mão de obra qualificada.

Roberto Guedes (2008) indicou o exercício de dado ofício como um mecanismo de mobilidade, embora destacando que tal mobilidade para forros, perpassava de maneira geracional, o autor destaca que para muitos libertos, as artes mecânicas eram maneiras de alcançar uma mobilidade social dentro do próprio grupo (estamento) ao qual estava inserido.

Outros tantos libertos em testamento foram mencionados como detentores de um ofício especializado. Em 1855 Tereza Lopes de Jesus ratificou a alforriou de seus

34 CMA. Fundo Testamentos; Testamento de Claudina Rosa de Almeida, 1846. Caixa 7.

${ }^{35}$ HDBN. O Liberal do Pará (PA), 17/10/1878, p. 3.

Revista da ABPN • v. 12, n. Ed. Especial - Caderno Temático: "Africanos, escravizados, libertos biografias, imagens e experiências atlânticas” • agosto de 2020, p. $344-369$ 
escravos Escolástica e Clemente, os quais deveriam permanecer na companhia da herdeira, ficando em seu poder o moleque Clemente para mandar ensinar um ofício e igualmente ter em seu poder a preta Escolástica se ela o quiser. ${ }^{36}$ João Francisco ficava forro em 1855 pelos bons serviços prestados no ofício de pedreiro; ${ }^{37}$ no testamento de Anastácia Jose Malcher o preto carpina Dionizio ficaria forro após um ano de trabalho para pagar as despesas dos sufrágios e missas da testadora. ${ }^{38}$ Em 1874, Tereza de Assunção deixa forro seus escravos, sendo que "o obrigará a acabar de aprender o ofício de sapateiro e findo 5 anos se dará carta de liberdade, o mesmo a sua irmã Ricarda, servirá no prazo de 5 anos e então será forra. ${ }^{39}$

O aprendizado de um ofício não só servira para os herdeiros do testador ao usufruírem do serviço do liberto, como ao próprio liberto na medida que potencializava sua autonomia durante a liberdade. Aos poucos a valorização do trabalho manual era o elemento definidor entre os libertos que seriam taxados de vadios e os considerados de "bons costumes". Para além das expectativas dos grupos dirigentes os egressos de escravidão sabiam se valer de tais visões e em certa medida a compartilhavam.

Quando Lucinda Antônia Maria da Conceição, liberta pela lei do 13 de Maio, requisitou a tutela de seus filhos Arthur e Adolfo, provavelmente sabia que suas chances de manter a guarda dos menores eram parcas dada a frequente recusa dos juízes em nomear as mães tutoras de seus filhos, ainda mais uma ex-escrava. ${ }^{40}$ Neste sentido requisitou que a tutela fosse dada ao mestre sapateiro Joaquim da Costa Freitas, "querendo dar-lhes uma boa educação".

Para o preto Salustiano Felippe, natural do Maranhão, quando livre pela Lei do treze de maio, veio em busca de sua neta na cidade de Belém. ${ }^{41} \mathrm{Um}$ dos requisitos para conseguir a tutela da mesma era demonstrar ser trabalhador. O "defeito mecânico" que durante boa parte do período colonial assim como no Império foi indicado como um dos elementos que limitavam a ascensão de determinados grupos (visto a sociedade brasileira hierarquizada), foi ao longo do século XIX acionado para promover certo grau

\footnotetext{
${ }^{36}$ CMA. Fundo Testamentos; Testamento de Tereza Lopes de Jesus, 1855. Caixa 10.

${ }^{37}$ CMA. Fundo Testamentos; Testamento de Ana Josefa Alves de Ataíde, 1855. Caixa 10.

${ }^{38}$ CMA. Fundo Testamentos; Testamento de Anastácia José Malcher, 1859. Caixa 11.

${ }^{39}$ CMA. Fundo Testamentos; Testamento de Thereza de Assumpção Madureira Pantoja, 1874. Caixa 23.

${ }^{40}$ CMA. Fundo Autos de Tutela; autos de tutela dos menores Arthur e Adolfo, 1888.

${ }^{41}$ CMA. Fundo Autos de Tutela; Tutela da menor alexandrina, 1889.
}

Revista da ABPN • v. 12, n. Ed. Especial - Caderno Temático: "Africanos, escravizados, libertos biografias, imagens e experiências atlânticas” • agosto de 2020, p. $344-369$ 
de mobilidade, seja no aspecto econômico com o acumulo do pecúlio, ou mesmo na inserção social em uma camada de trabalhadores livres.

É importante perceber que mobilidade alcançada por libertos, era em suma instável, seus diversos marcadores assentados na cor, gênero e status jurídico poderiam e seriam usados quando necessários. Neste cenário a formação e participação de libertos e homens livres de cor em associações mutualistas tais qual a Imperial Sociedade Beneficente Artística Paraense possibilitava a aquisição de direitos, e auxílio em dados conflitos.

Entre os fundadores da ISBAP (fundada em 26 de junho de 1867) estavam negros, mulatos e pardos, naturais do Pará, Rio de Janeiro, Pernambuco e Maranhão. ${ }^{42}$ Em 1868 a mesma Sociedade possuía 113 membros, seu estatuto definia certos padrões de comportamento, sendo os "bons costumes" como um dos elementos preponderantes para tornar-se sócio. O seu primeiro presidente foi Simeão Estellita dos Reis Guimaraes, natural de Pernambuco, segundo Ferreira Brandão (2018), Simeão aportou no Pará em 1854, teve destaque na sociedade Belenense, em 1868 obteve 131 votos para ocupar o cargo de votante na paroquia de Sant'Anna conseguido apenas o cargo de suplente oposicionista. Simeão casou-se em setembro de 1857 na paroquia da Sé, sua noiva chamava-se Maria da Encarnação Martins Mascarenhas, Simeão e Maria eram filhos de Francisca Maria das Chagas e Tereza de jesus Martins respectivamente, ambos filhos de pais incógnitos.

Quando do testamento do mestre ferreiro Manoel Francisco Correa em 1869, encontrei entre seus testamenteiros Simeão Estellita dos Reis. ${ }^{43}$ Percebe-se que para além do associativismo, os profissionais das artes mecânicas constituam uma rede de solidariedade horizontal.

Outro sócio da ISBAP que aparece nos testamentos é João Antônio Corrêa de Bulhões com 28 anos de idade em $1881 .{ }^{44}$ Em suas últimas vontades declarou ser filho

\footnotetext{
42 Segundo pesquisa de Mathias Ferreira Brandão, os fundadores da Artística paraense foram: “Guilherme Possidonio Borges, natural do rio de Janeiro, negro, serralheiro; Simeão Estellita dos Reis Guimarães, pernambucano, negro, alfaiate; Luis Thomaz Espindola, paraense, mulato, musico; João Florêncio de Melo, paraense, empregado público; Francisco de Paula Ribeiro, paraense, ourives; Inocêncio José Mendes, paraense, ferreiro; Laurindo Augusto das Neves, maranhense, negro, barbeiro; João Onofre Damasceno, paraense, santeiro e Raimundo Carneiro de Lima Tupiassu, maranhense, alfaiate".

${ }^{43}$ CMA. Fundo Testamentos; Testamento de Manoel Francisco Corrêa, 1869. Caixa 17.

${ }^{44}$ CMA. Fundo Testamentos; Testamento de João Antônio Correa de Bulhões, 1881. Caixa 29.
}

Revista da ABPN • v. 12, n. Ed. Especial - Caderno Temático: "Africanos, escravizados, libertos biografias, imagens e experiências atlânticas” • agosto de 2020, p. 344-369 
de Juliana Maria Machado e pai incógnito, contudo nomeava como seu primeiro testamenteiro ao seu homônimo João Antônio Correa de Bulhões (seria este um pai ilegítimo ou ex-senhor?). Ao verificar os registros de casamentos da Cúria Metropolitana de Belém encontrei um João Antônio Correa de Bulhões como testemunha do casamento dos escravos Damião e Rufina, em outubro de 1870. Ao ser testemunha do casamento de escravos pode-se entrever relações de solidariedade, e a possibilidade de que João Antônio Corrêa, fosse na realidade um liberto, ou simplesmente uma pessoa de cor.

Outros libertos que aparecem entre os membros da ISABP são Alberto Francisco Acapú, Vergolino Antonio de Sousa, Joaquim Jose de Santa Anna. Também identifiquei a presença de outros associados como testamenteiros de mulatos e libertos. No testamento da liberta Brigida Maria da Conceição feito em 1886 aparece como testamenteiro Bento Carlos de Sousa, ${ }^{45}$ este consta na relação de associados da ISBAP em 1868. Em 1885 foi nomeado terceiro testamenteiro de Manoel Luiz Junior que teve uma filha com a escrava Damásia Veríssima da conceição. Seu nome consta na lista de votantes de 1878, com 48 anos de idade, filho de Ricarda Maria do Espírito Santo, sabia ler, e possuía renda de $600 \$ \$ 000$ réis. $^{46}$

Em 3 de setembro de 1856 foi detido na cadeia de Belém, por embriagues e briga, o liberto Felippe Nery da Silva. Este nome consta entre os sócios do ISBAP em $1868 .{ }^{47}$ Ele também é indicado como um dos beneficiários no testamento do português Januário Antônio da Silva, dono do engenho Bom Intento, entre os vários libertos para os quais legou casas e dinheiro estava o nome de Felippe:

Deixo ao mulato Severo Lucio da Silva dois quartinhos de casa que possuo na rua das flores, número cento e setenta e oito, cento e oitenta e um conto de reis em moeda corrente. Deixo ao mestre barbeiro Felippe Nery da Silva um quarto de casas na rua das flores número cento e oitenta e dois, e também lhe deixo um conto de reis em moeda corrente. Deixo ao mulato barbeiro Miguel Lucio de Paiva um quarto e casas na rua das flores... ${ }^{48}$

\footnotetext{
${ }^{45}$ CMA. Fundo Testamentos; Testamento de Brígida Maria da Conceição, 1886. Caixa 34.

${ }^{46}$ HDBN. O Liberal do Pará (PA), 09/10/1878, p. 2.

${ }^{47}$ HDBN. Treze de Maio (PA), 05/09/1856, p.4.

${ }^{48}$ CMA. Fundo Testamento; Testamento de Januário Antônio da Silva, 1870. Caixa 20.
}

Revista da ABPN • v. 12, n. Ed. Especial - Caderno Temático: "Africanos, escravizados, libertos biografias, imagens e experiências atlânticas” • agosto de 2020, p. 344-369 
Já o liberto Alberto Francisco Acapú foi alforriado no testamento de mão comum de Jacinto Jose Ferreira e Maria Carolina Marques, feito em 1863, seus senhores haviam contraído matrimonio em outubro de 1841 , ambos eram portugueses. ${ }^{49}$ Eles possuíam quatro escravos chamados Gregória, Francisco, Alberto e Martinha, sendo esta última designada como paralitica. Alberto era o único mulato do plantel, todos os cativos ficaram forros após a morte de ambos os testadores. Além da alforria, Alberto tornou-se herdeiro de um quarto de casas na Rua dos Inocentes com a condição de dar 320 reis diários a cafuza Martinha, o que totalizaria $9 \$ 600$ réis mensais, neste caso conheciam a capacidade de Alberto para acumular pecúlio.

Entre as centenas de cativos mencionados em testamentos muitos tornaram-se herdeiros de seus senhores, obtendo a posse ou usufruto de casas, dinheiro, joias e ferramentas de trabalho. Alberto pode por meio dos bens recebidos e de sua qualificação manter-se, e galgar espaços na sociedade local, pude encontrá-lo em várias notas de jornais ao longo do período de 1869 a 1881 . Em maio de 1869 em um anúncio de fuga de escravos, constava que Alberto tornou-se tutor do órfão Nicolau T. Candido de Carvalho, e estava à procura da escrava Mirandolina pertencente a herança do dito órfão. ${ }^{50}$ Para tornar-se tutor era necessário provar ser capaz de cuidar e educar um menor, assim como ser considerado uma pessoa idônea ante aos olhos das autoridades judiciarias, neste sentido o fato de ser proprietário de uma casa e ter trabalho são elementos importantes para adquirir tal status.

Ao que os jornais permitem vislumbrar, Alberto foi nomeado tutor por meio da tutela testamentária, ou seja, foi escolhido pelos pais do menor em testamento. Ele não só assumiu o encargo de tutor, como também o de testamenteiro do finado professor Francisco Candido de Carvalho. ${ }^{51}$ Trabalhou como caixeiro em várias casas comerciais de Belém. ${ }^{52}$ Sua esposa possuía o mesmo sobrenome da família de seu tutelado indicando que as relações de confiança com Francisco se produziram a partir do enlace com Francisca Cândida de Carvalho. Este último foi professor de Latim no Liceu

\footnotetext{
${ }^{49}$ CMA. Fundo Testamentos; Testamento de mão comum de Jacinto Jose Ferreira e Maria Carolina Marques, 1863. Caixa 12.

${ }^{50}$ HDBN. Diário de Belém (PA): folha política, noticiosa e comercial. 12/05/1869, p. 4.

${ }^{51}$ HDBN. Jornal do Pará (PA), 23/06/1869, p. 2.

52 HDBN. O Liberal do Pará (PA), 28/11/1871, p. 3; Almanak: Administrativo, Mercantil e Industrial (PA) - 1869, p. 120.
}

Revista da ABPN • v. 12, n. Ed. Especial - Caderno Temático: “Africanos, escravizados, libertos biografias, imagens e experiências atlânticas” • agosto de 2020, p. 344-369 
Paraense durante a década de 1850 e 1860, também ocupou o cargo de diretor de instrução publica da Província a partir de $1855 .{ }^{53}$

Em 1876 um artigo publicado no O Liberal do Pará o cônego Siqueira Mendes foi acusado de ter lançado "fora das qualificações mais de dois mil de votantes" e "ainda seiscentos são chamados de véspera para virem provar no dia seguinte seus direitos de cidadão". Em sequência foi apresentado uma lista de cidadãos da paroquia da Trindade que foram excluídos pelo cônego, entre os nomes estava o de Alberto Francisco de Acapú, assim como de dezenas de profissionais das artes mecânicas. Entre os listados havia 05 alfaiates, 05 carpinas, 02 fogueteiros, 1 ferreiro, 02 funileiros, 03 comerciantes, 06 sapateiros, 03 pedreiros e 2 pintores, também serralheiro, um talhador, operário, ourives e marítimo, e apenas dois proprietários, 1 empregado público. Alberto foi designado como caixeiro despachante. ${ }^{54}$

$\mathrm{O}$ direito de ser votante era um dos principais elementos que caracterizavam a cidadania oitocentista. Ao excluir um número significativo de artífices da qualificação de cidadãos votantes, Siqueira Mendes estava estabelecendo limites à cidadania de libertos. Por certo as questões que envolveram as disputas entre o partido Liberal e Conservador na província paraense estavam em jogo, e afetaram as pretensões de livres e libertos de cor no Pará.

No jornal A Constituição foi dada a resposta. ${ }^{55}$ Declarou falsas as acusações do articulista de $O$ Liberal do Pará, publicou-se uma outra lista, agora a dos cidadãos qualificados como votantes, e nesta constava o nome de Alberto, com 34 anos, viúvo, caixeiro despachante, sabia ler, filho de pais incógnitos, morador na praça D. Pedro II, com uma renda legal de $800 \$ \$$ réis.

Neste cenário de busca por cidadania, participar de Associações de Auxilio Mútuos poderia significar ampliar a participação política, tais associações podem ser tomadas como plataformas politicas ante as pressões promovidas em dadas circunstancias, um exemplo foi o projeto de regulamentação do serviço doméstico em Belém após a abolição da escravidão, quando foi pensado inserir a "classe dos Artistas" no mesmo projeto, sendo retirado nas discussões da câmara de Belém.

\footnotetext{
${ }^{53}$ HDBN. Treze de Maio (PA), 17/11/1855, p. 2.

${ }^{54}$ HDBN. O Liberal do Pará (PA), 07/07/1876, p. 1.

${ }^{55}$ HDBN. A Constituição (PA), 05/05/1876, p.3.
}

Revista da ABPN • v. 12, n. Ed. Especial - Caderno Temático: "Africanos, escravizados, libertos biografias, imagens e experiências atlânticas" • agosto de 2020 , p. $344-369$ 
Alberto Francisco Acapú apareceu novamente nos jornais como passageiro do vapor Gurupi vindo do Maranhão. Ainda em 1877 ele solicitou a junta comercial da capital para ser nomeado "avaliador das fazendas de secos e molhados, prédios urbanos, escravos e semoventes". ${ }^{56}$ Pode-se notar a aspirações de Alberto em galgar espaços e melhores condições por meio do seu trabalho.

Após 18 anos do testamento de seus senhores, foi a vez de Alberto deixar registrado suas últimas vontades em $1881 .{ }^{57} \mathrm{Em} 1881$ Alberto já havia perdido a mãe, esposa e seus doze filhos, sua filha Raimunda Cândida de Carvalho Acapú falecera um ano antes, com apenas dezessete anos de idade, ela nasceu apenas um ano após o testamento dos ex-senhores de seu pai. Certamente o falecimento de seus familiares estava guardado com pesar e desolação, descreveu a exata hora do falecimento de sua esposa: fui casado com Francisca Julia Cândida de Carvalho Acapú, falecida no dia quatro de fevereiro de mil oitocentos e setenta e quatro, as doze horas e dez minutos da manhã.

Sua finada esposa foi ministra da Venerável Ordem Terceira da Penitência para o ano de $1869 .{ }^{58}$ As Ordens Terceiras franciscanas fundadas em Portugal no século XVII se estabeleceram no Brasil ao longo do período colonial. A Ordem terceira da Penitência fundada em Belém durante vários anos no século XVIII recusava a receber entre seus membros negros, pardos e mulatos, já em um momento onde os estatutos de pureza de sangue não mais vigiam na referida ordem, vide o caso exposto no primeiro capítulo. Tal espaço tradicionalmente congregava homens e mulheres, indo além dos aspectos devocionais, dedicavam-se a prestar assistência aos necessitados, cuidados médicos e "amparo na morte".

Provavelmente sua esposa e demais filhos tiveram os cuidados do enterro providos pela Ordem Terceira. Em 1884 a direção da Ordem em Belém solicitou que os familiares das pessoas enterradas, entre agosto de 1880 e janeiro de 1881, a exumar os restos mortais visto terem de começar de novo o enterramento no primeiro quadro do cemitério desta Venerável Ordem em Santa Izabel. Entre os nomes dos finados estava o

\footnotetext{
${ }^{56}$ HDBN. O Liberal do Pará (PA), 11/07/1877, p. 1; 27/07/1877, p. 2.

${ }^{57}$ CMA. Fundo Testamentos; Testamento de Alberto Francisco Acapú, 1881. Caixa 29.

${ }^{58}$ HDBN. Almanak: Administrativo, Mercantil e Industrial (PA) - 1869, p. 507.
}

Revista da ABPN • v. 12, n. Ed. Especial - Caderno Temático: "Africanos, escravizados, libertos biografias, imagens e experiências atlânticas” • agosto de 2020, p. 344-369 
de Raimunda Cândida de Carvalho Acapú. ${ }^{59}$ Belém teve seu primeiro cemitério público inaugurado em 1850, sob a administração da Câmara Municipal, porém em função da resistência calcada no costume dos enterramentos promovidos por ordens religiosas a administração do mesmo passou para as mãos da Santa Casa da Misericórdia. Em 1860 o governo provincial concedeu para que algumas ordens construíssem seus Cemitérios (Silva, 2005).

Segundo Guilhermina Motta (2015), aos ministros competiam o governo temporal das Ordens Terceiras, neste caso a posição ocupada pela esposa de Alberto era de significativa importância dentro da Ordem. Ao casar-se com Francisca ele conseguiu galgar mais um degrau em seu processo de mobilidade, o prestígio e assistência que poderia ter no vínculo com tal instituição seriam elementos importantes em sua vida. Em testamento deixou à Ordem Terceira de São Francisco duzentos mil reis para ajudar no reparo do hospital.

Como sua mãe Thomazia, filhos e esposa já eram falecidos, logo não possuía herdeiros forçados, distribui dinheiro entre seus afilhados, aos pobres e cegos da capital, deixou três quadros para a Ordem terceira, assim como um baú com desenhos escolares às professoras protegidas da mesma ordem. Também declarou suas poucas dívidas com três alfaiates indicando um gasto frequente nas suas vestimentas, provavelmente ligado ao seu trabalho de caixeiro.

Entre seus bens não houve menção a casa herdada na Rua dos Inocentes em 1863, constava uma caderneta da Caixa Econômica no valor de 1 conto e 745 mil réis; em mãos do pianista George Wacker um piano e mais pertences; dentro de uma mala amarela com objetos de ouro; um colar com duas medalhas, 1 pulseira, 1 alfinete de peito com um camafeu, 1 par de brincos imitando uma folha de parreira, outro par de brincos pequeno, outro de mãozinha com perola fina, 1 par de botões de orelha com rubi, três anéis, e outro de cobra que tem consigo, 1 volta de ouro estimada no valor de $400 \$ 000$, quatro malas, incluindo uma para senhoras e um Bau de folha envernizado.

Os itens listados, particularmente os objetos de ouro provavelmente pertenciam a sua esposa e filha, e demonstram o refinamento da família de Alberto, assim como o piano que estava em poder de George Wacker deve ter pertencido a finada filha do

\footnotetext{
${ }^{59}$ HDBN. O Liberal do Pará (PA), 14/03/1884, p. 3.
}

Revista da ABPN • v. 12, n. Ed. Especial - Caderno Temático: "Africanos, 
liberto. Ao longo do século XIX as mulheres das classes dominantes dedicavam-se a tocar piano como uma forma de refinamento, em reuniões particulares elas por vezes entretinham os convidados com suas habilidades musicais. Entre os elementos dos programas de ensino de várias escolas de moças na capital paraense, constavam aulas de piano e prendas domésticas, o ensino feminino formal dedicava-se a formar boas mães $e$ donas do lar (Bezerra Neto, 2005).

O que se pode constatar é que da escravidão até o seu falecimento, Alberto Francisco Acapú utilizou ao máximo os instrumentos que permitiriam sua mobilidade. Enquanto escravo, sua relação com os senhores possibilitou ser comtemplado pela alforria, suas qualificações permitiram viver sobre si, por meio de redes, casamentos, compadrio, e associações galgou um lugar que pouco parece lembrar tratar-se de um liberto.

\section{CONCLUSÕES}

Em meio ao processo de consolidação de uma nova ética do trabalho ao longo do século XIX no Brasil, escravos e libertos foram também valeram-se das transformações econômicas locais e globais, estabelecendo suas posições ao ressignificar suas atividades que por séculos foram tidas como "menores", que desqualificavam os sujeitos dedicados as artes mecânicas ante uma estrutura social fundada em hierarquias raciais. Ser liberto no Pará oitocentista foi estar continuamente afirmando sua condição, ao mesmo tempo que buscavam meios de alargar seus direitos. Não coube ao Estado brasileiro, ou a grupos políticos como os liberais ou conservadores a ampliação de direitos, as lutas gestadas nas relações cotidianas tiveram papel central nas transformações vivenciadas no mundo do trabalho paraense.

$\mathrm{O}$ uso de trajetórias mesmo que fragmentarias possibilita ter acesso a outras narrativas da presença negra no século XIX. No Grão-Pará a prática da alforria por verba testamentaria, somado as outras modalidades de manumissão proporcionaram a existência de um contingente de homens e mulheres que saíram da escravidão. A racialização teve um peso significativo para estes milhares de sujeitos que emergiram da escravidão.

Revista da ABPN • v. 12, n. Ed. Especial - Caderno Temático: "Africanos, escravizados, libertos biografias, imagens e experiências atlânticas” • agosto de 2020, 
Para lidar com as múltiplas formas de interdição da liberdade, estes egressos do cativeiro, teceram laços verticais e horizontais de solidariedade, seja nas irmandades negras, ou nas sociedades beneficentes e de ofícios. No caso do Pará, mesmo após a abolição negros, mulatos e pardos, continuaram a buscar algo além da liberdade, acesso a espaços, a bens e a família e tensionaram a noção de cidadania.

\section{REFERENCIAS BIBLIOGRÁFICAS}

BEZERRA NETO, José Maia. Pensando a Educação Feminina. Iaras. Publicação do Grupo de Estudos e Pesquisas Eneida de Morais - GEPEM, Belém, v. 1, p. 07 - 07, 01 dez. 2005.

BRANDÃO, Mathias Ferreira. Filhos do Trabalho, Irmãos na Beneficência: A Sociedade Artística Paraense, 1867-1874, p. 60-61. Monografia de conclusão de curso; FAHIS/UFPA 2018.

FRAGA, Walter. Encruzilhadas da Liberdade: história de escravos e libertos na Bahia (18701910). $2^{\text {a }}$ Ed. Rio de Janeiro: Civilização Brasileira, 2014.

GUEDES, Roberto. Egressos do cativeiro: trabalho, família, aliança e mobilidade social. Porto Feliz; 2008.

LIMA, Ana Renata do Rosário de. Terra e trabalho como componente das lutas cabanas no Acará-PA (século XIX). ANPUH - XXV SIMPÓSIO NACIONAL DE HISTÓRIA - Fortaleza, 2009. Ver também: LIMA, Ana Renata do Rosário de Revoltas Camponesas no Vale do AcaráPA (1822-1840). Dissertação de Mestrado, PPGDSUT/NAEA/UFPA, 2002.

LOBO, Marcelo F. Direito e Escravidão: as ações de liberdade nos tribunais de Belém século XIX. Trabalho de conclusão de curso. UFPA, FAHIS, 2011.

MOTA, Guilhermina. Os Ministros da Ordem Terceira De S. Francisco de Coimbra No Século XVIII: Perfil Social, Famílias, Redes De Poder. Biblos. Número 1, 2015 • 3. ${ }^{a}$ série; pp. 311-343.

PALHA, Barbara da Fonseca. Escravidão negra em Belém: mercado, trabalho e liberdade (1810-1850). Dissertação (Mestrado) - Universidade Federal do Pará, Instituto de Filosofia e Ciências Humanas, Programa de Pós-Graduação em História, Belém, 2011.

REIS, João José; GOMES, Flavio dos Santos; CARVALHO, Marcus J. M.O Alufá Rufino: tráfico, escravidão e liberdade no Atlântico negro (c.1822-c..1853). de. $-2^{\mathrm{a}}$ ed. São Paulo: Companhia das Letras, 2017.

SALES, Mábia Aline Freitas \& MOURÃO, Leila. Hierarquias, fortunas e artigos importados em Belém, 1840-1870. Revista Trilhas da História. Três Lagoas, v.2, n4 jan-jun 2013. p.24-47.

SILVA, Érika Amorim. O cotidiano da morte e a secularização dos cemitérios em Belém na segunda metade do século XIX (1850/1891). Dissertação (Mestrado em História Social) PUCSP. São Paulo, 2005. p. 68-69.

Revista da ABPN • v. 12, n. Ed. Especial - Caderno Temático: "Africanos, escravizados, libertos biografias, imagens e experiências atlânticas” • agosto de 2020, p. $344-369$ 
SILVA, José Antônio Novaes da. Doutor Tito Lívio de Castro: novas luzes sobre a trajetória de vida de um inesperado médico negro na capital do brasil oitocentista. Revista da Associação Brasileira de Pesquisadores/as Negros/as (ABPN), v. 10, n. 25, 2018, p. 43-68

Recebido 03/07/2020

Aprovado em 22/07/2020

Revista da ABPN • v. 12, n. Ed. Especial - Caderno Temático: "Africanos, escravizados, libertos biografias, imagens e experiências atlânticas" • agosto de 2020, p. 344-369 